\title{
Peridynamic Simulations of the Tetragonal to Monoclinic Phase Transformation in Zirconium Dioxide
}

DOI:

10.1016/j.commatsci.2017.09.001

\section{Document Version}

Accepted author manuscript

Link to publication record in Manchester Research Explorer

\section{Citation for published version (APA):}

Platt, P., Mella, R., DeMaio, W., Preuss, M., \& Wenman, M. R. (2017). Peridynamic Simulations of the Tetragonal to Monoclinic Phase Transformation in Zirconium Dioxide. Computational Materials Science, 140.

https://doi.org/10.1016/j.commatsci.2017.09.001

\section{Published in:}

Computational Materials Science

\section{Citing this paper}

Please note that where the full-text provided on Manchester Research Explorer is the Author Accepted Manuscript or Proof version this may differ from the final Published version. If citing, it is advised that you check and use the publisher's definitive version.

\section{General rights}

Copyright and moral rights for the publications made accessible in the Research Explorer are retained by the authors and/or other copyright owners and it is a condition of accessing publications that users recognise and abide by the legal requirements associated with these rights.

\section{Takedown policy}

If you believe that this document breaches copyright please refer to the University of Manchester's Takedown Procedures [http://man.ac.uk/04Y6Bo] or contact uml.scholarlycommunications@manchester.ac.uk providing relevant details, so we can investigate your claim.

\section{OPEN ACCESS}




\title{
Peridynamic Simulations of the Tetragonal to Monoclinic Phase Transformation in Zirconium Dioxide
}

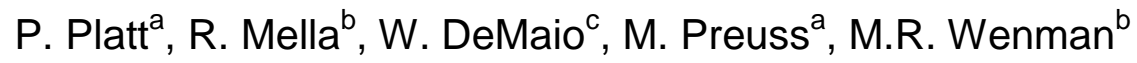 \\ a University of Manchester, School of Materials, Materials Performance Centre, Manchester, M13 9PL, \\ UK \\ ${ }^{b}$ Nuclear Department, Defence Academy of the UK, HMS Sultan, Military Road, PO12 3BY, UK \\ ${ }^{c}$ Massachusetts Institute of Technology, Department of Nuclear Science and Engineering, 77 \\ Massachusetts Ave., Cambridge, MA 02139, USA \\ ${ }^{d}$ Centre for Nuclear Engineering and Department of Materials, Imperial College London, London, SW7 \\ $2 A Z$
}

\section{ABSTRACT}

Whether present as a manufactured stabilised ceramic, or as an oxide layer on zirconium alloys, mechanical degradation in zirconia is influenced by the tetragonal to monoclinic phase transformation. Peridynamic theory was implemented within the Abaqus finite element framework to understand how the tetragonal to monoclinic phase transformation can itself cause fracture in zirconia. In 2D these simulations represent a single grain, transforming via an isometric dilational expansion, surrounded by a homogenous monoclinic oxide. The effect of transformation time, applied bi-axial pressure, and the fracture strain were assessed using the change in strain energy and the amount of damage in the oxide surrounding the transformed grain. Reducing the applied compressive stress or applying a tensile stress reduces the transformation strain energy. The introduction of a fracture strain leads to damage in the surrounding oxide region largely in the form of cracks, and reduces the transformation strain energy further by reducing the constraint on the transforming grain. The extent of the fracture, and reduction in constraint on the transformed grain, is more significant with the application of a biaxial tensile pressure.

\section{Introduction}

Whether used as an engineering ceramic, or present as an oxide layer grown thermally on zirconium alloys, zirconium dioxide demonstrates distinctive behaviours that centre on the tetragonal to monoclinic phase transformation. In either system the mechanisms for room temperature stabilisation, and potentially destabilisation, are the same. The addition of doping elements to manufactured zirconia has been shown to stabilise the tetragonal phase at room temperature (Duwez et al., 1951; Wang and Atkinson, 2011). A number of these elements are present as alloying elements in commercial zirconium alloys (Beck and Kaliba, 1991, 1990; Ghigna et al., 1999; Jiang et al., 1999; Li and Chen, 1994). Recent work using X-ray absorption near edge spectroscopy (XANES) (Hulme et 
al., 2015), and density functional theory (DFT) (Bell et al., 2015), has indicated that solid solution tin incorporated into the oxide layer should be present in both $\mathrm{Sn}^{2+}$ and $\mathrm{Sn}^{4+}$ oxidation states. The reduction of tin in zirconium-niobium alloys has been shown to produce oxide layers with a lower tetragonal phase fraction (Frankel et al., 2013; Wei et al., 2013). A proposed theory behind this mechanism is that introducing a doping element with a lower valence state than $\mathrm{Zr}^{4+}$ may stabilise the presence of oxygen vacancies, which in turn distort the lattice and make the tetragonal phase more energetically favourable (Fabris et al., 2002; Guo and Schober, 2004; Ho and Tuan, 2011; Shukla and Seal, 2005). As zirconium alloys oxidise entirely due to the inward migration of oxygen ions (Cox, 2005), there should be an increasing concentration of oxygen vacancies approaching the metal-oxide interface from the oxide surface (Cox and Pemsler, 1968; Na Ni et al., 2011; Yoo, 2001). This could be a contributing factor to the increased tetragonal phase fraction close to the metal-oxide interface (Petigny, 2000).

The tetragonal phase of zirconia has been proven to be stabilised by the application of compressive hydrostatic pressure (Garvie, 1978). Zirconia thin films can experience residual biaxial compressive stresses of the order of MPa to GPa, whether the material is applied as a coating (Scardi et al., 2004; Teixeira and Andritschky, 1999), or formed during thermal oxidation (Béchade et al., 2000; Jacquot et al., 1996; Petigny, 2000; P. Platt et al., 2015b; Polatidis et al., 2013; Preuss et al., 2011; Zhang et al., 2010). It is possible to destabilise the tetragonal phase by applying a tensile hydrostatic stress e.g. ahead of an advancing crack tip (Chevalier et al., 2009). In engineering ceramics this mechanism is referred to as transformation toughening because of the resulting retardation of crack growth by the tetragonal to monoclinic phase change and its associated increase in volume (Budiansky, 1983; Evans and Heuer, 1980; Kelly and Francis Rose, 2002). Oxides formed on zirconium alloys in autoclave and reactor undergo a transition and acceleration in the corrosion kinetics that has previously been linked with the formation of a network of lateral cracks close to the metal-oxide interface (Bossis et al., 2001; Polatidis et al., 2013; Yilmazbayhan et al., 2006).

Exposure of manufactured zirconia to moist environments up to $400^{\circ} \mathrm{C}$ has been shown to cause the tetragonal phase to transform to monoclinic, this phenomenon is referred to as low temperature, or hydrothermal, degradation (Chevalier et al., 2009; Eichler et al., 2007; Guo and Schober, 2004; Shukla and Seal, 2005). These conditions are very similar to those experienced by oxidising zirconium alloys in nuclear reactors or autoclaves, and these oxide films also demonstrate a continuous reduction in tetragonal phase fraction and degradation in the protective character of the oxide layer (Petigny, 2000; P. Platt et al., 2015b; Polatidis et al., 2013; Preuss et al., 2011; Zhang et al., 2010). In both cases a key issue is the ingress of oxygen containing species. The tetragonal to monoclinic phase transformation is known to generate cracks (Chevalier et al., 2009; Kelly and Francis Rose, 2002 ), as a consequence of the $\sim 6 \%$ volumetric expansion and $\sim 16 \%$ shear strain upon transformation (Platt et al., 2014). Nano-scale cracks associated with this phase transformation have also been observed using transmission electron microscopy (TEM) in oxides formed on zirconium alloys (Bossis, 2002). In either scenario these cracks could create fast ingress routes for oxygen containing species, reducing the protective nature of the oxide film, or accelerating the rate of 
hydrothermal degradation. A fundamental challenge then is in understanding exactly how this phase transformation leads to crack formation.

Whether the transformation occurs in sintered zirconia, or in the zirconia oxide layer grown on zirconium alloys, there are numerous factors that impact the extent of transformation induced fracture. Typically these factors occur simultaneously and make a systematic, quantitative experimental assessment highly challenging. As such, this research aims to improve understanding by applying the peridynamics approach in a simulated study of a single grain phase transformation induced fracture in zirconia.

Previously, finite element analysis has been used to simulate the tetragonal to monoclinic phase transformation (Platt et al., 2014). This work highlighted how relaxation of the in-plane biaxial compressive stress, or the application of a triaxial tensile stress, could destabilise the tetragonal phase. The volumetric expansion and shear strain associated with the transforming grain induced very high levels of stress in the surrounding oxide layer. However, these simulations did not include fracture. The result was that the transformation strain energy was artificially very high, and information on the likely crack formation was limited. Simulation of fracture in FEM is difficult due to the strong mesh dependence and requirement for crack branching criteria. XFEM offers improved results, but still has the problem that the use of classical partial differential equations leads to singularities at crack surfaces and tips (Beckmann et al., 2013). At a singularity, as the distance to the crack tip tends towards zero the mesh size must approach zero and the stress increase towards infinity. An alternative approach to the simulation of fracture proposed by Silling is that of peridynamics (Silling, 2000).

Peridynamics is a formulation of non-local solid mechanics theory that uses displacements, rather than spatial derivatives, to define the movement of nodes relative to one another (Kilic and Madenci, 2010a). By calculating the displacements of points connected within a defined cut-off distance known as the horizon, the peridynamics approach uses an integral formulation of a constitutive model (Beckmann et al., 2013). As such peridynamics does not lead to the formation of singularities, and shows much less mesh dependence than FEM, in the presence of defects such as cracks and voids. It also means the stress fields are, provided the mesh is adequately refined, both finite and convergent. However, in peridynamics the definition of material properties is dependent on a specific network of truss elements. As each node is connected to every other node within a defined horizon, there is a natural reduction in the number of connections constraining the nodes at the edge of a simulation. This reduction in constraint of the edge nodes effectively reduces the stiffness of this part of the network. This is typically corrected for by the appropriate application of boundary conditions and material properties.

The present work combines the peridynamics approach with finite element analysis to assess the tetragonal to monoclinic phase transformation in zirconium oxides. This includes factors affecting destabilisation, and prediction of the how the phase transformation can induce crack formation. 


\section{Model Construction}

\subsection{Peridynamics and Material Properties}

The peridynamics method was implemented into the commercial FE code Abaqus as describe in detail in (Beckmann et al., 2013). The explicit version was used to model the dynamics of the transformation and cracking. In peridynamics the material is represented by a series of material points (nodes in Abaqus). Mass elements were tied to each node and the material volume is dependent on the distance between material points, calculated with the bulk material density. In these simulations the nodes are connected by a network of truss elements which carry the force. This is done over a circular (2D) or spherical (3D) horizon (h). The horizon has been shown to give good results for reasonable computation time for a horizon of 3 lattice or material point spaces and this is what was used here (Beckmann et al., 2013). The force carrying truss elements need to be tuned to give the correct bulk material elastic response. A sensitivity study has been carried out for the elastic modulus that was applied to the individual truss elements in order to generate a mesh that has an elastic modulus equivalent to that of zirconia (253 GPa) (P. Platt et al., 2015b). As this is a bond based $2 \mathrm{D}$ peridynamics simulation, equivalent to a pair potential method in the atomic scale method, the Poisson ratio is fixed as 1/3 (Beckmann et al., 2013).

In this work a square $F E$ mesh was tied to the peridynamics mesh so that $\varepsilon_{11}, \varepsilon_{22}$, and $\varepsilon_{12}$ strain components could be determined for the peridynamic truss network. The continuum elements to which the truss elements have been tied do not contribute towards the stress in the simulation. As such, negligible values have been assigned for the elastic modulus ( $\left.E=1 \times 10^{-6} \mathrm{MPa}\right)$ of the continuum elements. Peridynamics distributes material mass only to the material points/nodes, as such the density of all of the elements has also been defined as a negligible value of $5 \times 10^{-10} \mathrm{~g} / \mathrm{cm}^{3}$. The point masses applied to the nodes in the simulations generate an overall material density equivalent to that of zirconia $\left(5.68 \mathrm{~g} / \mathrm{cm}^{3}\right)$.

In order to incorporate damage into the model, a history dependent critical mechanical strain was applied to the truss element in the surrounding oxide region. Beyond this strain the bond will lose all stiffness for the remainder of the simulation. This critical strain is correlated with the strain energy release rate using equation 1, derived from the Griffith criteria for creating two new surfaces over the area of one whole horizon (Silling et al., 2007).

$$
S_{0}=\sqrt{\frac{5 \pi G_{0}}{9 h E}}
$$

Where $h$ is the horizon distance and $G_{0}$ is the total energy per unit crack surface necessary to totally separate two halves of a material (Kilic and Madenci, 2010b). $S_{0}$ is one of the primary factors under investigation. This study tested four critical fracture strains defined as $0.00711,0.00553,0.00395$ and 0.00237 , which gives fracture stresses of $1.8 \mathrm{GPa}, 1.4 \mathrm{GPa}, 1 \mathrm{GPa}$ and $600 \mathrm{MPa}$. These values are 
based on the fracture stresses and strains defined for manufactured stabilised zirconia (Eichler et al., 2007, 2004; Noguchi and Fujita, 1989), and values obtained for zirconia formed as an oxide layer on ZIRLO $^{\text {TM }}$ (Platt et al., 2016). After a truss element has reached $S_{0}$, and failed, the elastic modulus of the truss becomes negligible $\left(E=1 \times 10^{-6} \mathrm{MPa}\right)$. Here we used a zero order model of fracture, i.e. once $S_{0}$ is reached the truss reduces in stiffness without further strain.

\subsection{Geometries and Boundary Conditions}

The simulation presented includes a single zirconia grain surrounded by a homogenous oxide. The simulation includes a layer of continuum reduced integration elements overlaid by a network of truss elements which represents the peridynamics mesh. The geometry of the entire simulation is $16 \mu \mathrm{m}^{2}$, and the central grain has a diameter of $1.2 \mu \mathrm{m}$ (Fig.1). Material point spacing was $0.1 \mu \mathrm{m}$ and therefore the horizon was $0.3 \mu \mathrm{m}$. A basic parametric study of the model size was carried out to define as large a model as possible relative to the size of the central grain, whilst balancing against available computing power. It is worth noting that the peridynamics formulation is neither plane strain or plane stress. Instead it is an approximation of a 3D model with a finite thickness based on the material point volume. Fig. 2 shows a schematic of the central grain volume represented by the peridynamics and finite element simulations.

Symmetry boundary conditions have been applied to the first three rows of nodes on the bottom and left hand edges of simulation (Fig.3). These boundary conditions fully constrain displacement perpendicular to each edge face, but allow for displacement parallel to the edge face. This is done to ensure artificial edge effects are avoided (Beckmann et al., 2013). A range of stress states are possible in zirconia as an engineering ceramic, or as an oxide formed on zirconium alloys. A standard Abaqus FE simulation was used to calculate the nodal displacements necessary to induce the required bi-axial compressive and tensile stress states. These calculated displacements were applied to three rows of nodes on the remaining edges of the simulation, and displace the nodes perpendicular to the edge faces. By fixing one edge in place whilst displacing the opposite edge a global stress state can be induced across the simulation. After the application of these nodal displacements, symmetry boundary conditions are applied restricting movement in the direction perpendicular to each edge. This system of boundary conditions has been summarised in Fig.3, and allows for the representation of a single transforming grain in a much larger bulk material.

\subsection{Phase Transformation}

\section{Volumetric Expansion}

Previous FE analysis investigated a range of transformation variants which gave a volumetric expansion of $\sim 6 \%$ and a shear strain of $\sim 16 \%$, both of which are well within the ranges defined in literature (Bailey, 1964; Budiansky, 1983; Heuer and Rühle, 1985; Qingping et al., 1990; Stam et al., 
1994). The impact of variant selection and anisotropic material properties are not the main focus of this work, therefore for simplicity, the phase transformation has been simulated as a dilatational volumetric expansion. This is implemented via the hydrostatic strain, calculated from the strain tensors defined in (Platt et al., 2014), and shown in equation 2. The phase transformation has been represented as a volumetric or dilatational expansion via the expansion of a central set of truss elements (Fig.1). Each truss element within this central region increases in length by $0.019(1.9 \%)$ in line with the hydrostatic strain defined in Eq.2 and the calculated strain tensors in (Platt et al., 2014). It should be noted that expansion strains were not been applied to the continuum mesh. The continuum mesh is tied to the truss mesh only as a means of mapping the strains.

$$
\varepsilon_{(100)_{t} / /(100)_{m}}=\left[\begin{array}{ccc}
0.0013 & 0 & 0.08125 \\
0 & 0.02647 & 0 \\
0.08125 & 0 & 0.02924
\end{array}\right]=\left[\begin{array}{ccc}
0.019 & 0 & 0 \\
0 & 0.019 & 0 \\
0 & 0 & 0.019
\end{array}\right]
$$

\section{Phase Transformation Rate}

Of particular interest in this work is the impact of the phase transformation rate on fracture behaviour. An upper limit for this is based on the speed of sound in zirconia, which can be defined using equation 3 (Fukuhara and Yamauchi, 1993).

$$
c_{z}=\sqrt{\frac{G_{z}}{\rho_{z}}}=\sqrt{\frac{83000}{5.68 \times 10^{-9}}}
$$

Where $C_{z}$ is the speed of sound in zirconia, $G_{z}$ is the shear modulus for zirconia (Chan et al., 1991), and $\rho_{z}$ is the density of zirconia (Chan et al., 1991). All values were taken for polycrystalline material, and an assumption is made that these values are similar to that of single crystal zirconia. This gives a speed of sound in bulk zirconia of $3.82 \times 10^{6} \mathrm{~mm} \mathrm{~s}^{-1}$. Assuming transformation of the grain begins in the centre and expands outwards, the upper limit for the time taken for the entire grain to transform can be calculated by the radius of the grain $\left(\sim 0.6 \times 10^{-3} \mathrm{~mm}\right)$ divided by the speed of sound in zirconia $\left(3.82 \times 10^{6} \mathrm{~mm} \mathrm{~s}^{-1}\right)$, giving a total transformation time of $1.6 \times 10^{-10} \mathrm{~s}$. Although researchers often define the martensitic transformation as being close to the speed of sound (Deville et al., 2004), this is very difficult to measure experimentally. It has even been suggested that martensitic transformations might occur at closer to around one third the speed of sound (Wolten, 1963).

Implementing this into the peridynamics simulation involved increasing the length of the truss elements up to a maximum over the period of the transformation time to simulate the isotropic expansion of the tetragonal grain. It should be made clear that the expansion is applied continually to all of the truss elements in the central region, i.e. the transformation does not initiate at the centre and then spread through the grain. A parametric study was carried out to analyse a range of transformation times from $5 \times 10^{-11} \mathrm{~s}$ to $3.4 \times 10^{-9} \mathrm{~s}$. The total simulation run time was $2 \times 10^{-8} \mathrm{~s}$, meaning that the damage recorded includes any continuation of damage after the phase transformation has completed. However, qualitative assessments indicated that any additional fracture was negligible for almost all of the transformation times. The stable time increment was calculated using the von Neumann stability criterion and the time increment was fixed as $1 \times 10^{-12} \mathrm{~s}$. 


\subsection{Transformation energy}

When a tetragonal zirconia grain transforms into the monoclinic phase there is a change in the energy associated with the grain. This change in total free energy can be described using the following relationship (Eq.4):

$$
\Delta W=\Delta G_{C}+\Delta U_{\text {STRAIN }}+\Delta U_{\text {SURFACE }}
$$

where $\Delta W$ is the change in total free energy, $\Delta U_{\text {STRAIN }}$ is the change in elastic strain energy and $\Delta U_{\text {SURFACE }}$ is the change in surface energy (including phase interfaces and crack surfaces). $\Delta G_{\mathrm{C}}$ is the change in chemical free energy when transforming from an unstable parent phase to a stable product phase. Both the surface and strain energies are positive whilst the chemical energy is negative. The change in total free energy must be negative for the transformation to proceed (Chevalier et al., 2009; Kelly and Francis Rose, 2002; Platt et al., 2014).

\section{Simulation Results \& Discussion}

\subsection{Transformation strain energy}

Using the continuum element mesh tied to the truss mesh it was possible to map the strains present in the simulation. Fig.4 shows the $\varepsilon_{11}$ and $\varepsilon_{22}$ components mapped by the continuum mesh for the central transformed grain, with no external applied pressure and no fracture of the surrounding truss elements. By isolating those continuum elements pinned to the truss representation of the transforming grain it is possible to define the change in strain energy as a result of the phase transformation. For a given continuum element each strain component was determined by subtracting the recorded strain after the transformation from the strain that would occur if it had been allowed to fully expand without constraint. Here the strain energy of a single element can then be calculated as follows for a plane strain formulation.

$$
U_{\text {STRAIN }}=\left(\frac{v G}{(1-2 v)}\left(\varepsilon_{11}^{2}+\varepsilon_{22}^{2}\right)+G\left(\varepsilon_{11}^{2}+\varepsilon_{22}^{2}\right)+2 G \varepsilon_{12}^{2}\right) A
$$

where $\varepsilon_{11}, \varepsilon_{22}$, and $\varepsilon_{12}$ are the strain components, $A$ is the area of the grain after transformation, and $G$ is the shear modulus. This method is similar to that of the Eshelby sequence used to calculate the elastic field associated with an ellipsoid inclusion (Eshelby, 1957; Kelly and Francis Rose, 2002). To test this approach a comparison was made with a 2D plane strain standard FE simulation, containing only continuum elements, whereby the central continuum elements are expanding directly to simulate the dilatational phase transformation. 
Fig. 5 shows a comparison of the strain energies extracted directly from a standard Abaqus FE simulation, calculated based on the FE strains, and calculated from the strain in the peridynamic simulations. Each point represents a separate simulation, and in each case fracture is not permissible. The strains are defined for the peridynamic simulations via a continuum mesh (zero mass and negligible stiffness) to which the load bearing truss element peridynamic network has been pinned. It can be seen that the calculated FE strain energies compare very well with those extracted directly from Abaqus. This gives a great deal of confidence in the application of equation 5 . The calculated strain energies for the peridynamics simulations demonstrate a very similar trend to that of the FE simulations, but with an overall reduction of $\sim 12 \%$. This difference is due to the reduced density of expanding truss elements at the interface. Fig. 6 shows the central truss elements overlaid onto the continuum elements, it can be seen that there are fewer truss elements that will expand at the edge of the central region when compared with the centre.

For clarity, all subsequent results relate to the peridynamics simulations. Fig.7 shows the change in strain energy of the transformed grain for different transformation times, with a fracture strain of 0.0024 and no applied pressure. Each point represents a separate simulation. Although there is some scatter, the results show that below $\sim 0.5 \times 10^{-9} \mathrm{~s}$ the transformation strain energy drops significantly. This difference in the strain energy with regards to transformation time can be explained by the impact on the fracture behaviour. Fig. 8 compares simulations carried out for transformation times of $1 \times 10^{-10}$ $\mathrm{s}$ and $1 \times 10^{-9} \mathrm{~s}$. The truss elements that have been fractured are shown as red, those that remain functional and load bearing are shown in blue. The reduced transformation time has significantly increased the number of fractured truss elements. An initial study of change in strain energy for a transformation time of $1 \times 10^{-10} \mathrm{~s}$, under different applied pressures, gave highly inconsistent and scattered results. Using this as a sensitivity study a transformation time of $1 \times 10^{-9} \mathrm{~s}$ was used for all subsequent simulations.

Fig.9 shows the change in strain energy for different values of applied biaxial compressive stress, a transformation time of $1 \times 10^{-9} \mathrm{~s}$, and based on fracture strains of $0.0024,0.004,0.0055$, and 0.0071 . This figure also includes the change in strain energy defined for simulations in which fracture is not permissible. In Fig.9 this data is referenced as "NoFrac.", however, it should be noted that this is the same data referenced as "Peri-Calc." in a comparison with standard Abaqus FE simulations in Fig.5.

Fig.9 demonstrates a general reduction in the change in strain energy with decreasing compressive stress, or increasing tensile stress. Also, where fracture is not permissible the relationship between the change in strain energy and applied pressure is very close to linear (Platt et al., 2014). This also appears to be the case when fracture is allowed and the stress state is strongly compressive. Under a strong compressive stress the magnitude of the stress state has a greater impact on transformation strain energy than the fracture strain. For an applied compressive stress of $1 \mathrm{GPa}$, reducing the fracture strain from 0.0071 to 0.0024 (a difference of 0.0047 ) only results in a $5 \mu \mathrm{J}(\sim 14 \%)$ reduction in

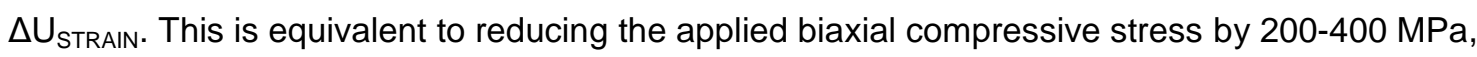
depending upon the fracture strain. Although there appears to be some deviation from linear at low 
levels of compressive stress, the impact of the fracture strain becomes more significant as the applied stress becomes tensile.

\subsection{Damage Analysis}

The damage fraction was assessed in these peridynamic simulations by taking the number of fractured truss elements and dividing this by the total number of truss elements in the oxide surrounding the central grain. This gave the damage fraction for the simulation as a whole. Fig.10 shows this damage fraction plotted against applied pressure for a transformation time of $1 \times 10^{-9} \mathrm{~s}$. As with the change in strain energy, there is a much greater effect from applying a bi-axial tensile stress than there is when the stress is bi-axial and compressive. Comparing Fig.9 and Fig.10 it appears that there is a strong link between the change in strain energy and the extent of the damage to the surrounding oxide layer. The reason for this is that the increased fracture has reduced the constraint on the transformed grain, and therefore, the change in strain energy is reduced.

Fig.11 is a composite image, showing the maximum in-plane principal strain for the central transformed grain, imposed onto an image of the fractured truss elements in the surrounding oxide for a fracture strain of 0.004 , with no applied external stress. Those regions of greatest strain in the central grain correspond well with those regions of the surrounding oxide that have experienced the most damage. Here, the greater strain is evidence of a reduction in constraint, corresponding to a lower change in strain energy. Much of the damage here effectively represents crack formation. However, the link between the damage fraction and the change in strain energy is not exact. From Fig. 9 it can be seen that simulations with an applied bi-axial tensile stress of $350 \mathrm{MPa}$ and fracture strains of 0.004 and 0.0055 have very similar values of $\Delta \mathrm{U}$. However, Fig.10 shows that those same simulations have quite different damage fractions. The implication is that after a certain amount of fracture, further damage has a negligible impact on the transforming grain.

Fig.12 shows an array of fracture patterns for applied stresses of $300 \mathrm{MPa}$ (tensile) to $1 \mathrm{GPa}$ (compressive), and for fracture strains from 0.0024 to 0.0071 . This gives a visual representation of the damage shown in Fig.10, and provides insight into the way in which damage is occurring. Comparing the output for fracture strains of 0.004 and 0.0024 , under an applied tensile stress of $300 \mathrm{MPa}$, there is a large difference in the damage fraction (Fig.10). Fig.12 illustrates that this is because the simulation has developed a second set of well-developed cracks. For all of the fracture strains studied, under an applied compressive stress of $1 \mathrm{GPa}$, damage is not represented by well-defined cracks but areas of failed truss elements. Although the damage fraction under this applied pressure is low (Fig.10), the failure of these truss elements has a large impact on the transformation strain energy (Fig.9).

The aim of applying a bi-axial tensile stress was to partly simulate the region ahead of an advancing crack tip. In oxides formed on zirconium alloys cracks are known to form parallel and close to the metal oxide interface (N. Ni et al., 2011; P Platt et al., 2015; P. Platt et al., 2015a), and perpendicular to the metal-oxide interface at higher temperatures (Omar et al., 2015; Parry et al., 2013). In both 
cases these cracks are linked with a significant reduction in the protective capacity of the oxide layer. If the advancing crack tip causes the phase transformation then the additional cracking could provide fast ingress routes for oxygen containing species (Bossis, 2002). In this situation, phase transformation induced fracture has been demonstrated using TEM (Ni et al., 2010). This fracture is said to be strongly linked with nano-pores formed along grain boundaries, which would correlate with an effective reduction in the fracture strength of the oxide surrounding a transforming grain. In manufactured zirconia coatings, the tetragonal to monoclinic phase transformation is known to arrest cracks due to the dilatational expansion (Chevalier et al., 2009). However, it has also been linked to the problem of crack micro-branching (Kirchner and Gruver, 1981; Nono, 2005), and is a significant problem associated with hydro-thermal degradation (Gaillard et al., 2008; Keuper et al., 2013).

\subsection{Chemical and Surface Energies}

Fracture strains of $0.00237,0.00395,0.00553$ and 0.00711 can be correlated with Equation 1 to give $G_{0}$ (the total energy per unit crack surface necessary to totally separate two halves of a material) [41]. These fracture strains therefore correlate with values for $G_{0}$ of $0.24 \mathrm{~J} / \mathrm{m}^{2}, 0.68 \mathrm{~J} / \mathrm{m}^{2}, 1.32 \mathrm{~J} / \mathrm{m}^{2}$ and 2.2 $\mathrm{J} / \mathrm{m}^{2}$. An important note here is the definition of $\mathrm{G}_{0}$, which rather than directly corresponding with any surface energy density is more representative of the difference between the surface energy density of a crack face and the energy densities of any pre-existing interfaces and surfaces such as grain boundaries or defects. The fracture strain or strength of a material is dependent upon the density and size of pre-existing cracks and defects. As a continuum simulation, well above the microscopic scale of defects, the only way that this formulation of peridynamics could incorporate an increased defect density is to reduce $S_{0}$ and concurrently $G_{0}$.

Garvie et al. have indicated that interfacial energies for monoclinic zirconia are not negligible, with coherent interfacial energy densities of $0.29 \mathrm{~J} / \mathrm{m}^{2}$ and partial interfacial energy densities of $0.73 \mathrm{~J} / \mathrm{m}^{2}$ [19]. Literature gives a mixed range of values for the free surface energy density of monoclinic tetragonal zirconia. Garvie et al. calculated a value of $\gamma_{m}=1.17 \mathrm{~J} / \mathrm{m}^{2}$ for monoclinic zirconia at RT [58], which was refined based on experimental data by Shukla et al. to give a value of $\gamma_{m}=0.98 \mathrm{~J} / \mathrm{m}^{2}[10]$. However, Christensen et al. used DFT simulations to define ranges of between $\gamma_{m}=1.25 \mathrm{~J} / \mathrm{m}^{2}$ and 2.5 $\mathrm{J} / \mathrm{m}^{2}$ depending on the crystallographic plane of the monoclinic phase [59]. Although there is a large amount of variation in the free surface energies provided by literature, they do indicate that the higher fracture strain simulations, with $G_{0}$ values of $1.32 \mathrm{~J} / \mathrm{m}^{2}$ and $2.2 \mathrm{~J} / \mathrm{m}^{2}$, better represent microstructures with very few or no grain boundaries and defects in the surrounding oxide. This is more comparable with the fracture strains and stresses obtained applying DIC to thin oxide layers on ZIRLO ${ }^{\mathrm{TM}}$ with smaller grains and defects (Platt et al., 2016), rather than those defined for manufactured stabilised zirconia containing larger grains and defects (Eichler et al., 2007, 2004; Noguchi and Fujita, 1989).

Garvie et al. also provided an equation to define the chemical free energy change $\left(\Delta G_{C}\right)$ with regards to temperature as $-285 \times 10^{6}\left(1-\frac{T}{1448}\right)$, where T is the temperature in Kelvin (Garvie and Swain, 
1985). For these simulations, under no applied pressures at temperature of $R T, 300^{\circ} \mathrm{C}$ and $900^{\circ} \mathrm{C}$ this gives values for $\Delta G_{C}$ of $-26.1 \mathrm{pJ},-19.8 \mathrm{pJ}$, and $-6.2 \mathrm{pJ}$. These values are much greater than those of $\Delta U_{\text {STRAIN }}$ and $\triangle U_{\text {SURFACE }}$ discussed in this manuscript, and as such it appears that the transformation should occur regardless of the applied load or fracture behaviour. $\Delta G_{C}$ could be reduced significantly by the introduction of oxygen vacancies (Shukla and Seal, 2005), either by doping elements (Li and Chen, 1994), or as a product of the oxidation of zirconium alloys (Ni et al., 2012). However, these results indicate that factors modifying the chemical free energy change could have the greatest impact on whether the phase transforms or not.

\subsection{Development \& Validation}

This study used a non-local continuum method for the simulation of the tetragonal to monoclinic phase transformation in zirconia. The results demonstrate the impact of fracture on the transformation strain energy under a range of applied pressures, and fracture strains. However, at the present level there are a number of limitations and simplifications that need to be considered. The two-dimensional nature of the simulation will artificially reduce the overall transformation strain energy as there is no constraint against expansion in the out-of-plane direction. Another necessary simplification was the removal of the shear component. This will reduce both the transformation strain energy and the localised strains, thereby fracture, and make a study of the twinning phenomena impossible (Platt et al., 2014). Future developments of this simulation need to include three-dimensional configurations, shear components and twinning. A previous peridynamics study on brittle solids has shown that it is now possible to create fully polycrystalline models of oxides incorporating texture effects. The model developed here produced predictions of the reductions in strain energy, with respect to applied stress and fracture strain for single grains. This information could be further used to calibrate polycrystalline approaches that may be able to capture full fracture behaviour (Ghajari et al., 2014).

The challenge of carrying out this research experimentally provides some justification to the use of simulation, but it also limits validation of the results. There is significant evidence for cracking that results from the tetragonal to monoclinic phase transformation in sintered zirconia. Typically, the tetragonal to monoclinic phase transformation causes undoped specimens to crumble during cooling, unless the grain size is nano-scale (Namavar, 2007). FIB-SEM has shown that the tetragonal to monoclinic phase transformation causes extensive fracture, particularly along grain boundaries, as a consequence of hydro-thermal degradation (Gaillard et al., 2008; Keuper et al., 2013). Cracking is also apparent when using TEM to study the phase transformation in oxides formed during the oxidation of zirconium alloys (Bailey, 1964; Bossis, 2002; Ni et al., 2010). This gives qualitative validation that cracks form under certain conditions.

From literature the phase transformation induced fracture does not appear to be as extensive in oxides formed on zirconium alloys, when compared with manufactured zirconia ceramics. Studies have correlated increased tetragonal phase fraction with the increased compressive stress in the oxide layer (Frankel et al., 2013; Polatidis et al., 2013). This compressive stress could also be the 
reason that phase transformation induced fracture is much less extensive in oxides formed on zirconium alloys. The combination of macro-scale compressive stresses, with a dual-phase anisotropic microstructure should lead to strong variations in micro-scale stresses in the oxide which could impact phase stability and fracture (Berdin et al., 2015). The macro-scale compressive stress, micro-scale stress concentrations, grain boundary porosity, and lateral crack distributions through the oxide layer all vary depending on the thickness of the oxide \& oxidation time relative to the transition points in the oxidation kinetics (Berdin et al., 2015; N. Ni et al., 2011; Ni et al., 2010; P Platt et al., 2015; P. Platt et al., 2015b; Polatidis et al., 2013; Swan et al., 2016). Given the range of simultaneously occurring factors in either of these material degradation scenarios attributing one experimental outcome to a specific input can be misleading.

\section{Conclusions}

Peridynamics has been used to analyse the effect of fracture strain and applied stress on the fracture resulting from the tetragonal to monoclinic phase transformation in zirconium dioxide for a single grain. In the absence of any fracture, reducing the applied biaxial compressive stress, or increasing an applied biaxial tensile stress, reduced the change in strain energy $\left(\Delta U_{\text {STRAIN }}\right)$ associated with the phase transformation. This effect was enhanced with the introduction of fracture. Reducing the fracture strain increased the amount of damage, reducing the constraint on the grain and thereby reduced $\Delta U_{\text {STRAIN. }}$ The relationship between $\Delta U_{\text {STRAIN }}$ and the applied stress state was close to linear under a strong compressive stress. The reduction in $\Delta U_{\text {STRAIN }}$ became more significant as the stress state approached zero and became tensile. Under applied biaxial tensile stress the simulations demonstrated a significant increase in the damage fraction in the surrounding oxide region. The results from this systematic study could be used to further calibrate a polycrystalline peridynamics model to predict fracture in oxides. 


\section{Figures}

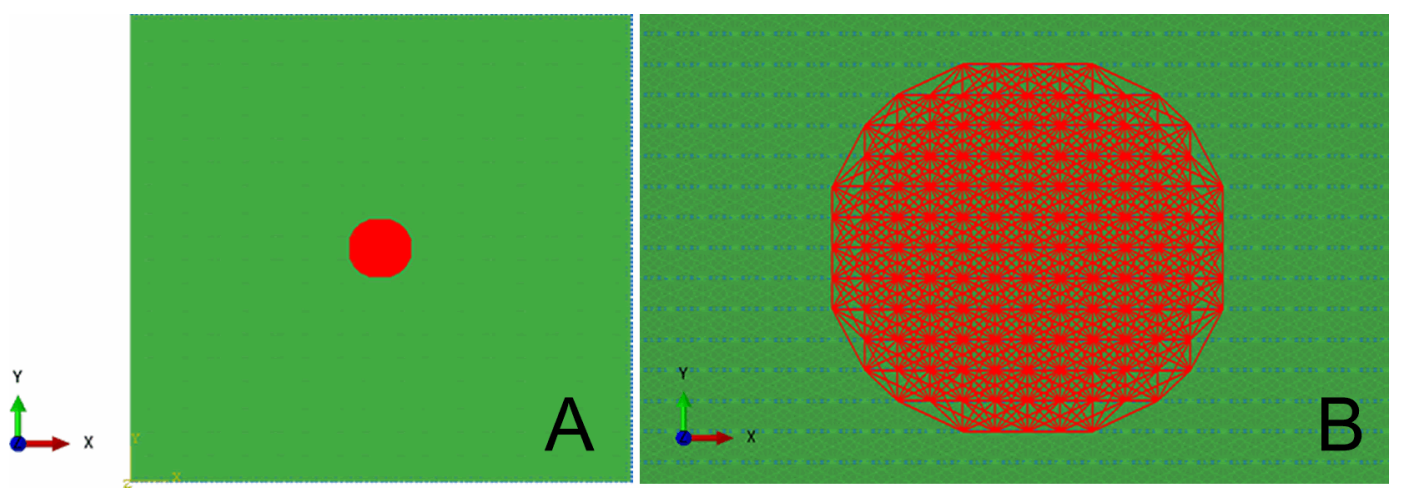

Figure 1: Images of the single grain. A illustrates the full model; and B shows the detail of the truss element mesh.

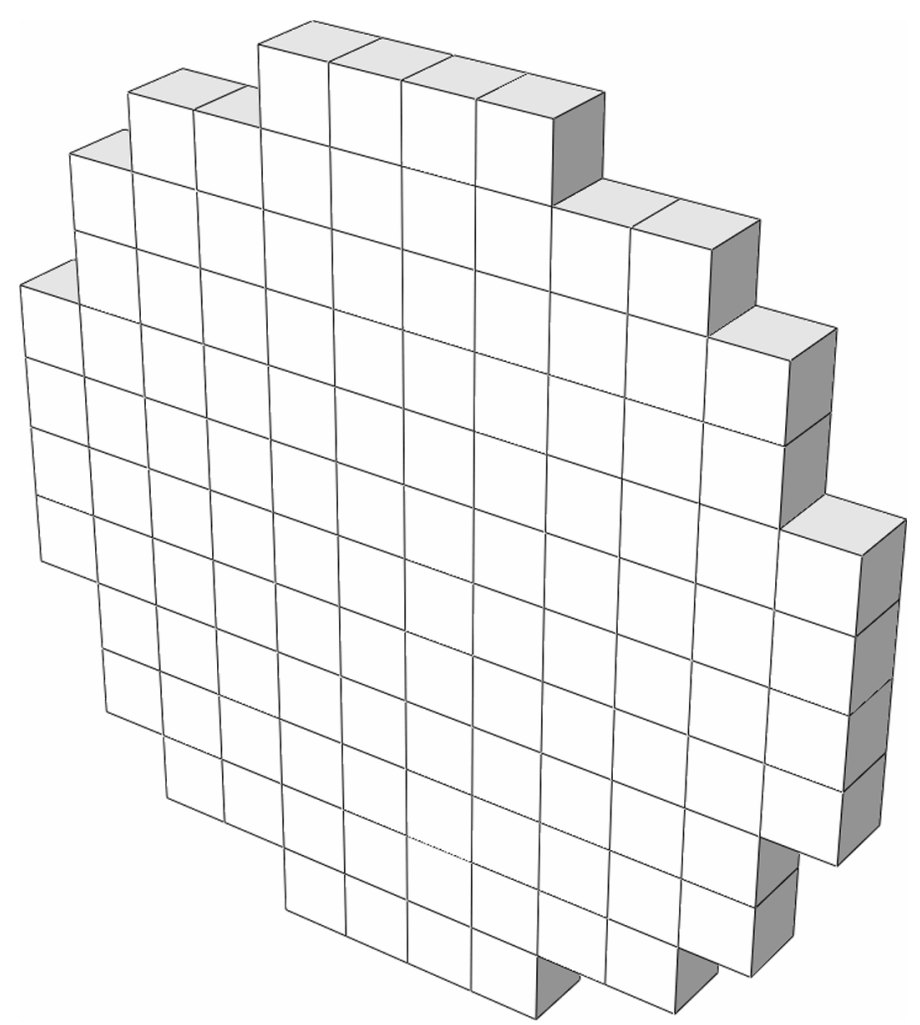

Figure 2: Schematic of the central grain volume described by the peridynamics and finite element simulations. 


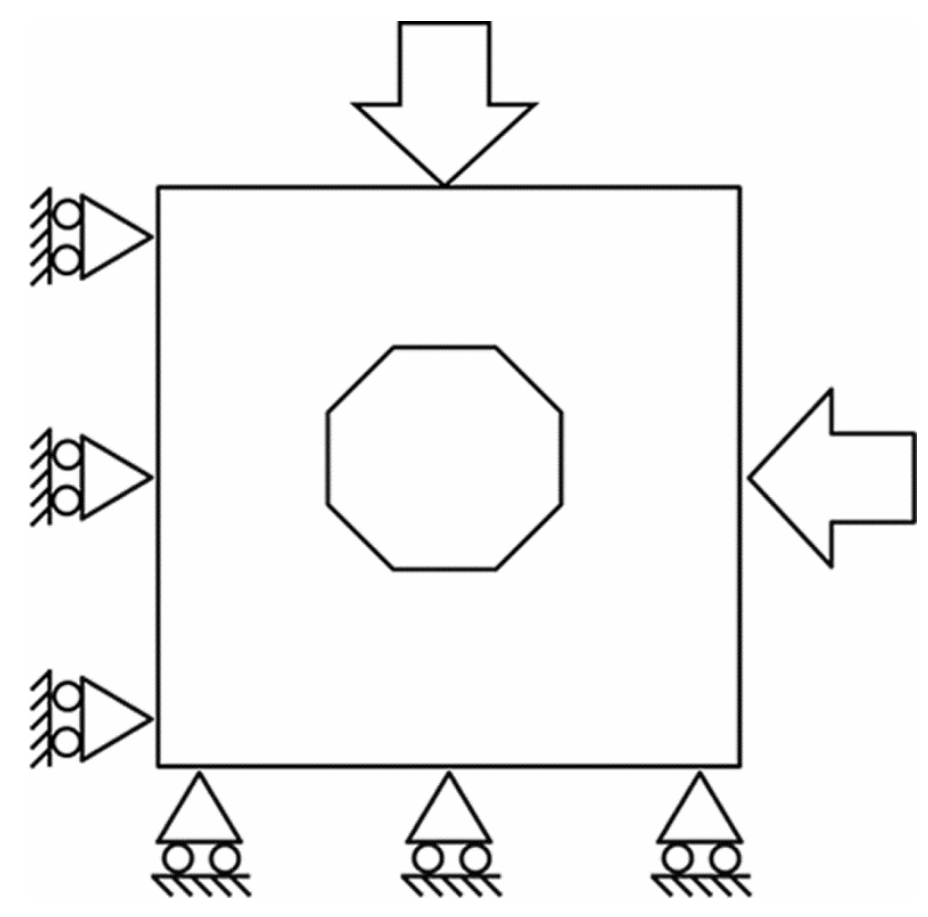

Figure 3: Schematic demonstrating the model's boundary conditions and load application.
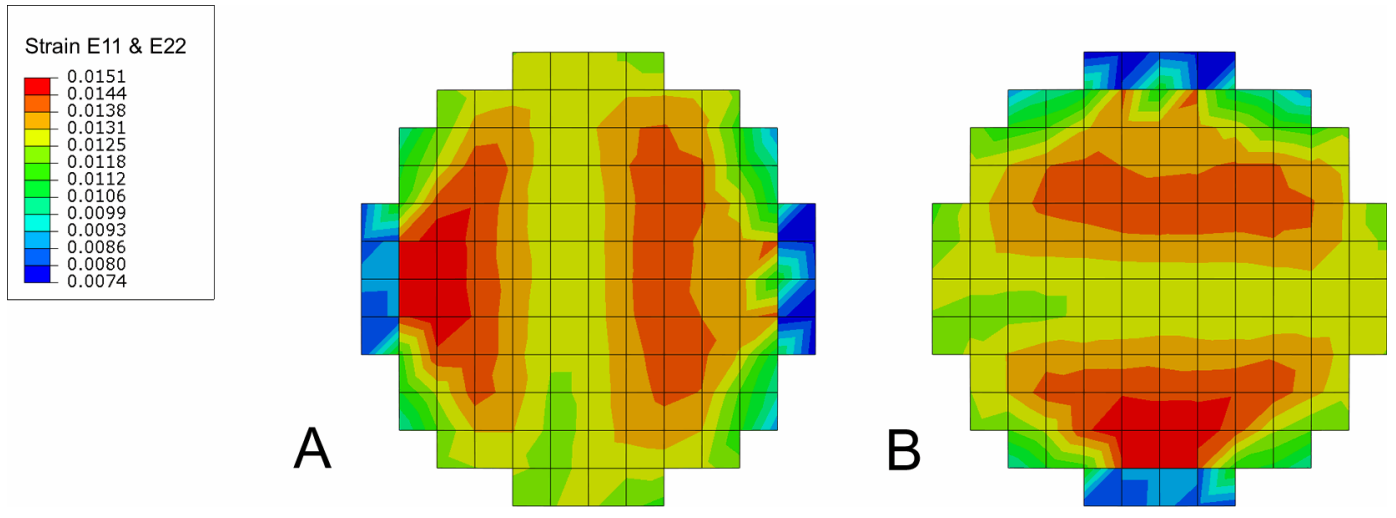

Figure 4: (A) $\varepsilon_{11}$ and $(B) \varepsilon_{22}$ components mapped by the continuum FE mesh for the central transformed grain, with no applied pressure and no fracture of the surrounding truss elements. 


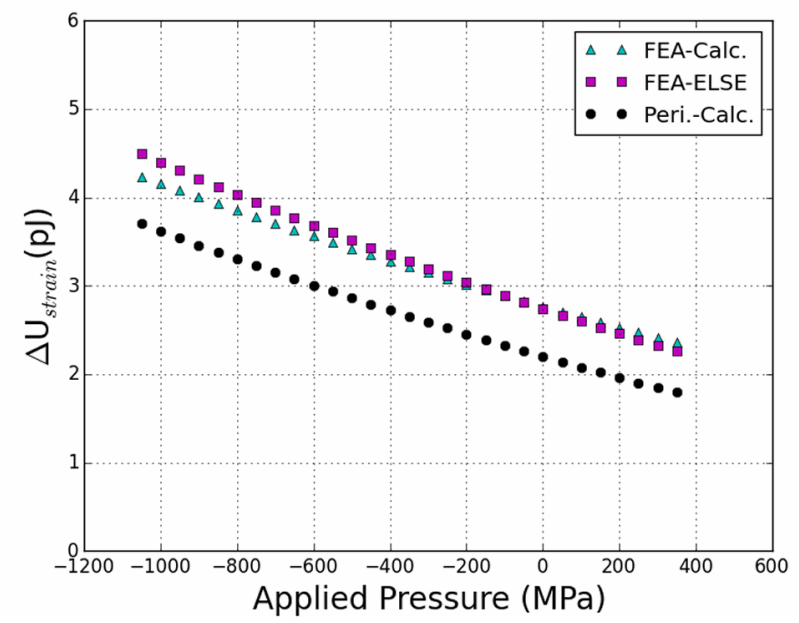

Figure 5: Comparison of the strain energies for the transforming grain; extracted directly from Abaqus (FE-ELSE), calculated from the FE strain results (FE-Calc.) and calculated from the strains defined in the peridynamics simulations (Peri.-Calc.).

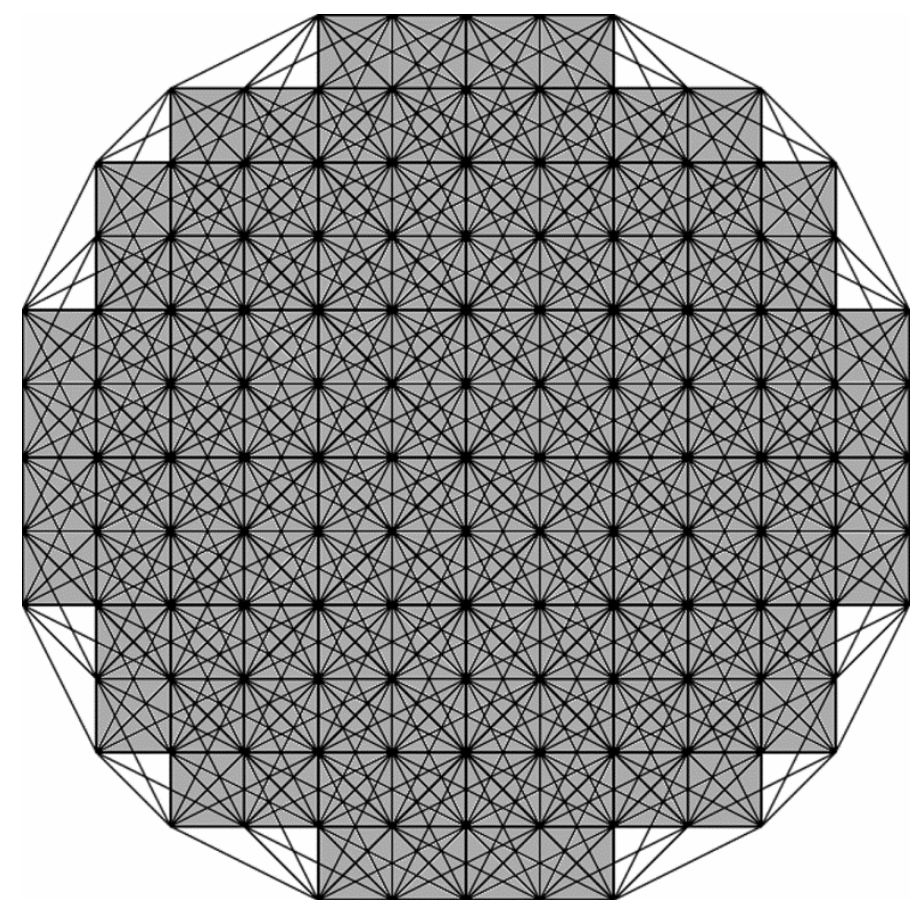

Figure 6: Central truss elements overlaid onto the central continuum elements. 


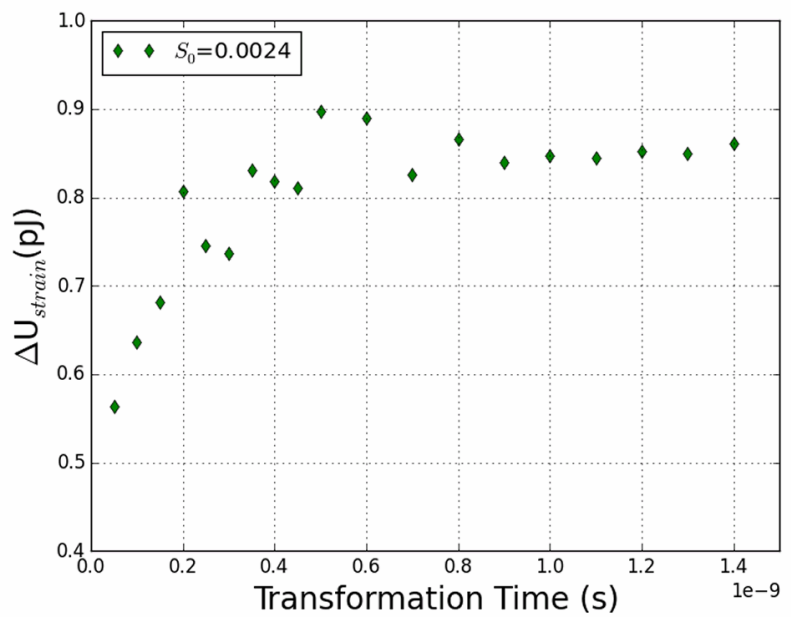

Figure 7: The impact of transformation time on the change in strain energy.

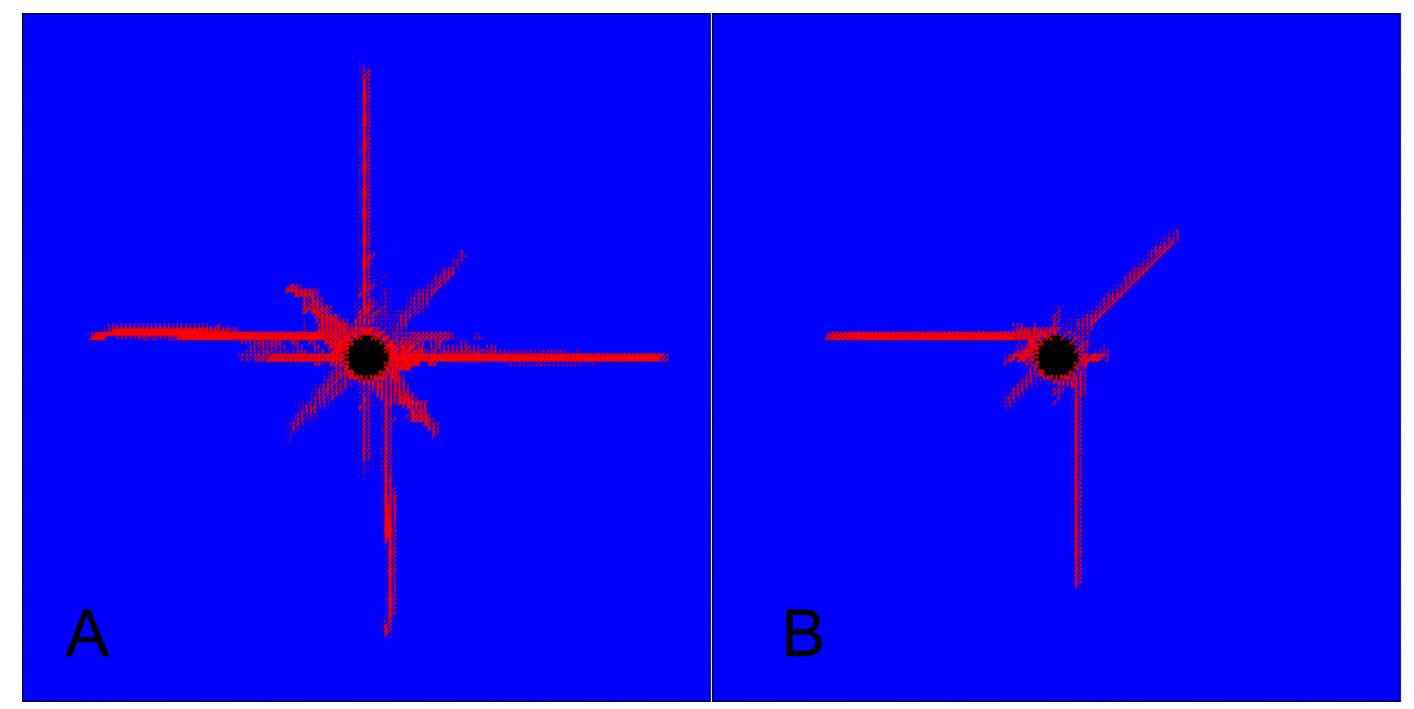

Figure 8: Illustrations of the fracture profiles for transformation times of $1 \times 10^{-10} \mathrm{~s}(\mathrm{~A})$ and $1 \times 10^{-9} \mathrm{~s}(\mathrm{~B})$, with a fracture strain of $\mathbf{0 . 0 0 2 4}$ and no applied pressure. (Note red indicates failed bonds). 


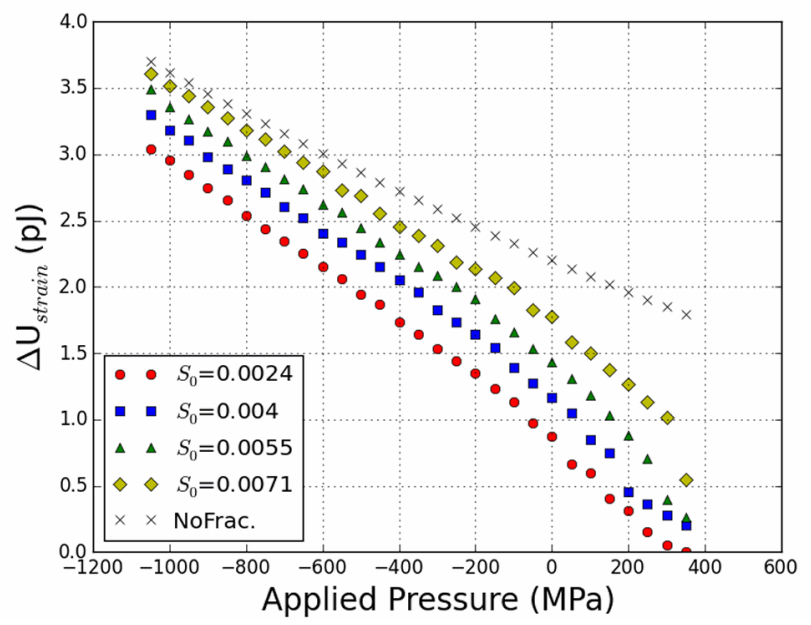

Figure 9: The change in strain energy for different applied bi-axial stress states, with a transformation time of $1 \times 10^{-9} \mathrm{~s}$, across a range of fracture strains.

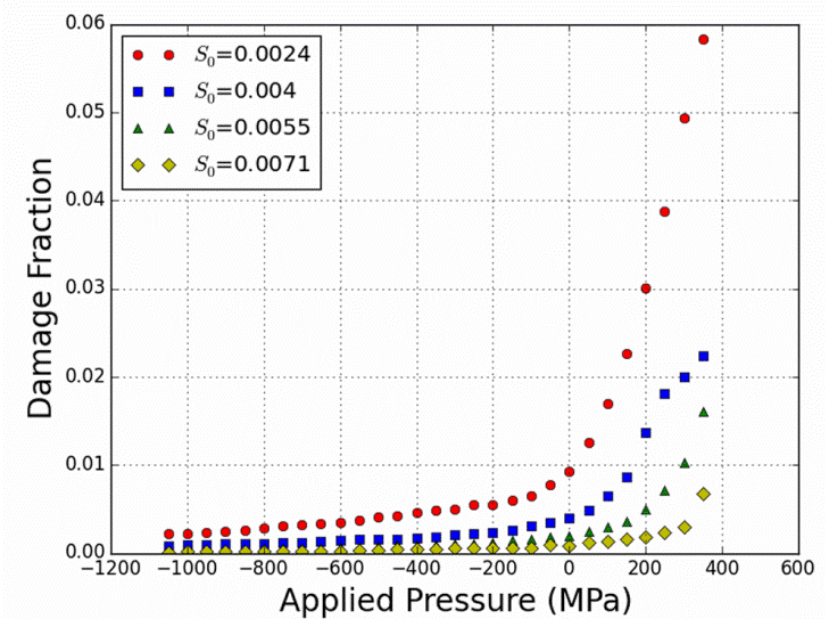

Figure 10: Fraction of broken truss elements in the surrounding oxide region for different applied bi-axial stress states, with a transformation time of $1 \times 10^{-9} \mathrm{~s}$, across a range of fracture strains. 

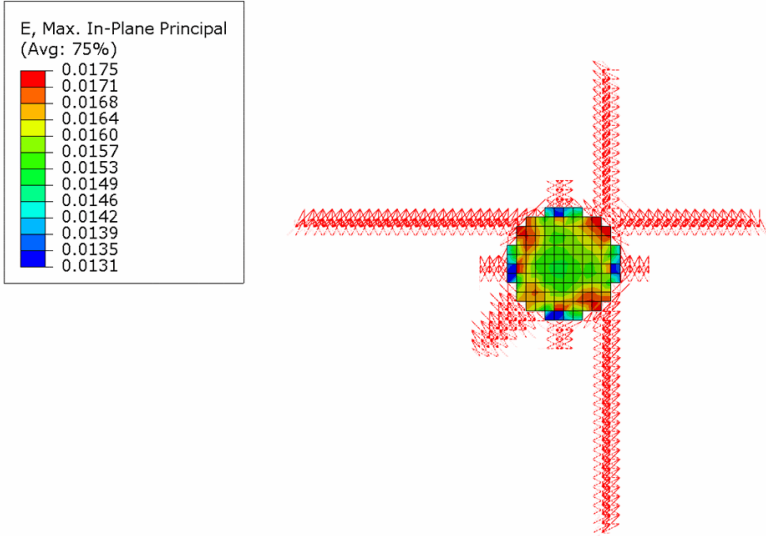

Figure 11: A composite image showing the maximum principal strain of the central grain (continuum elements) imposed on to fractured truss elements in the surrounding oxide region.

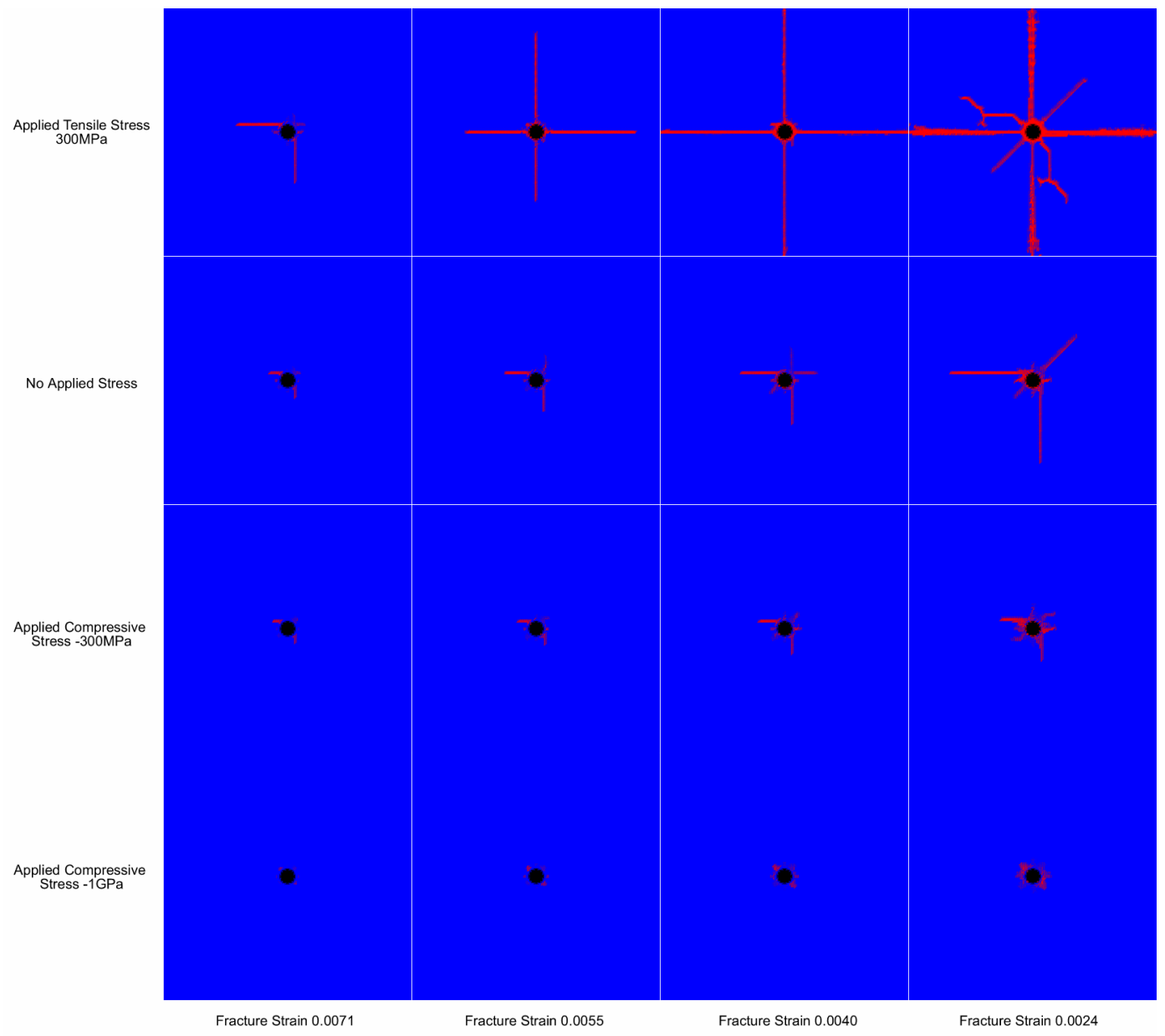

Figure 12: Array of fracture patterns for a range of different applied stresses and fracture strains. 


\section{Appendix}

\section{Verification Problem Definition}

To verify the implementation of peridynamics within the Abaqus FE framework a test case was analysed. The problem selected was an elastically loaded 2D plane strain plate containing a circular hole, as this exhibits both shear and normal stress. The simulation was a static load case where one side of the plate was fixed $\left(u_{1}=0\right)$ and the other has the uni-axial tensile stress applied. Three approaches were assessed; FE, peridynamics, and analytical.

The plate dimensions and stress sampling paths can be found in Figure A1. The elastic stress concentration for this problem is slightly greater than 3 . As a plane strain case the thickness is effectively infinite compared with the size of the hole. For both the FE and peridynamic simulations the hole was meshed with sufficient resolution to capture the hole curvature. The peridynamic simulation has the load and the fixed boundary conditions applied for a distance of two horizons into the material to avoid loading material surface effect. This model was created by converting a regular FE grid to a peridynamic mesh and then cutting a hole from the specimen. More details can be found in Table 1 .

Table 1: Finite element and peridynamic simulation information.

\begin{tabular}{|l|l|l|}
\hline & Finite Element & Peridynamic \\
\hline Plate width & $2 \mathrm{~m}$ & $1 \mathrm{~m}$ \\
\hline Inter-nodal spacing & $0.001 \mathrm{~m}$ & $0.001 \mathrm{~m}$ \\
\hline Hole radius & $0.05 \mathrm{~m}$ & $0.05 \mathrm{~m}$ \\
\hline Extension Load & $10 \mathrm{KPa}$ & $10 \mathrm{KPa}$ \\
\hline Poisson's ratio & 0.33 & 0.33 \\
\hline
\end{tabular}

\section{Verification Problem Results}

Figures A2 \& A3 plot the stress values found from post-processing the peridynamics simulation with the stress values found in the FE simulation, and those provided from an analytical solution. The stress is calculated in a similar manner to that in atomic scale simulations and details are given in (Zhou, 2003). Figure A2 provides $\sigma_{x x}$ and Figure A3 provides $\sigma_{y y}$. On the legends, the $Y$ values (red) refer to the vertical profile defined by the red line in Figure $A 1$, and the $X$ values (blue) refer to the horizontal profile defined by the blue line in Figure $A 1$. Based on these profiles and Figures $A 2 \& A 3$, the peridynamic simulations give stress values within $5 \%$ of the values provided by the FE simulations. Typically the peridynamic simulations slightly over-predict the stress when compared with the FE results.

The over-prediction of the stress is most apparent at the edge of the hole. Figure A4 plots $\sigma_{x y}$ taken from the circumference $1 \mathrm{~mm}$ from the hole centre (the hole edge) and from a circumference $3 \mathrm{~mm}$ from the hole centre ( $2 \mathrm{~mm}$ from the hole edge). Although the results at the edge of the hole are not well correlated, it can be seen that the stress distributions are themselves are consistent. 


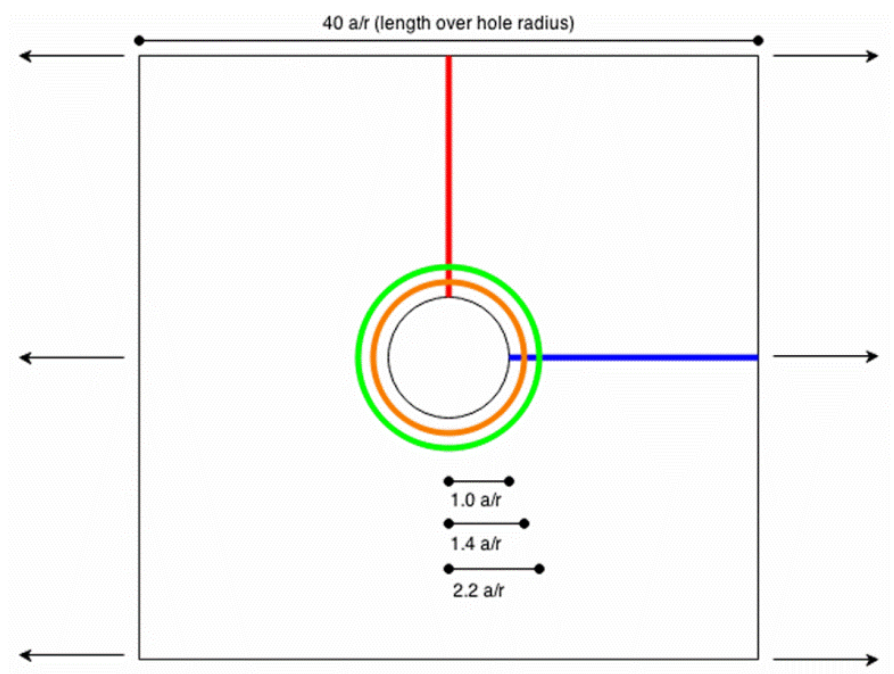

Figure A1: Schematic showing hole in a plate problem. The plate size is in units of length over the hole size (a/r). Paths from which the stresses are extracted include: red for y direction (vertical line), blue for the $\mathrm{x}$ direction (horizontal), and the circumferential lines indicating paths where the shear stress is sampled.

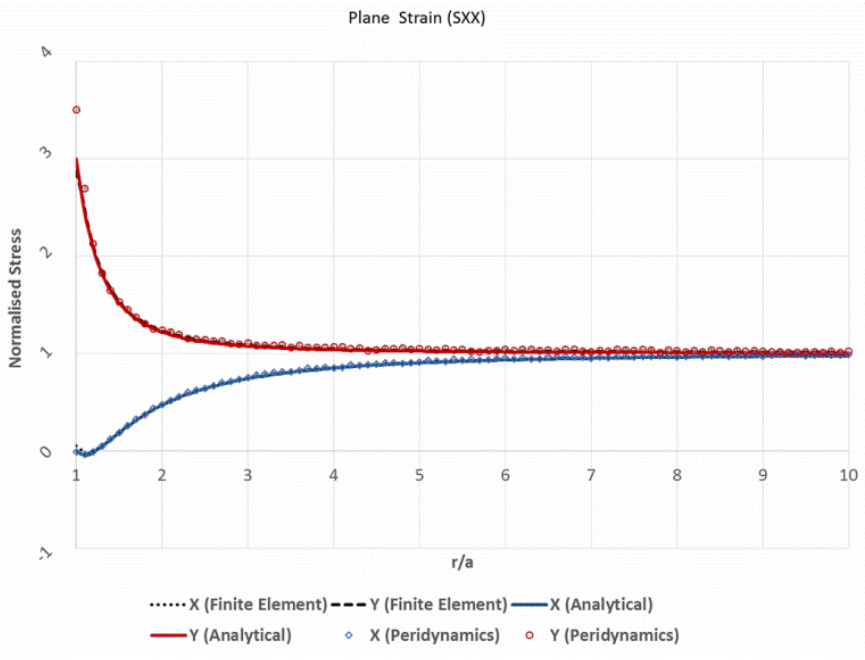

Figure A2: Plate with a hole $\sigma_{x x}$ stress component in the $\mathrm{x}$ and $\mathrm{y}$ directions for analytical, FE and peridynamics plane strain. 


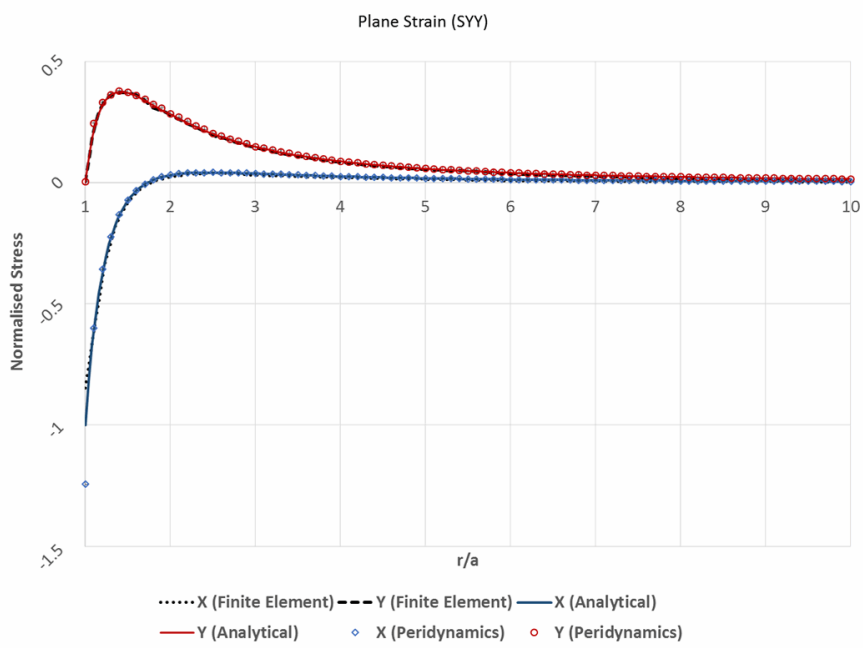

Figure A3: Plate with a hole $\sigma_{\mathrm{yy}}$ stress component in the $\mathrm{x}$ and $\mathrm{y}$ directions for analytical, FE and peridynamics plane strain.

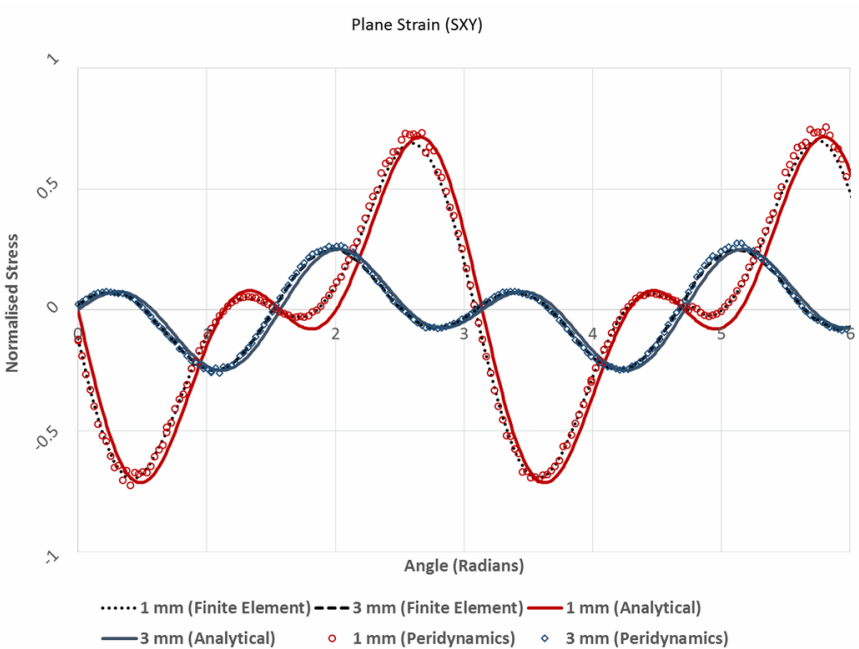

Figure A4: Plate with a hole $\sigma_{x y}$ stress component following paths paths parallel to the hole edge at $1 \mathrm{~mm}$ from the hole edge $(1.4 \mathrm{a} / \mathrm{r})$ and $3 \mathrm{~mm}$ from the hole edge $(2.2 \mathrm{a} / \mathrm{r})$ for analytical, $\mathrm{FE}$ and peridynamics.

\section{References}

Bailey, J., 1964. The monoclinic-tetragonal transformation and associated twinning in thin films of zirconia. Proc. R. Soc. Lond. A. Math. Phys. Sci. 279, 395-412.

Béchade, J.L., Dralet, R., Goudeau, P., Yvon, P., 2000. Studies of zirconium alloy oxide layers using synchrotron radiation, in: Materials Science Forum. Trans Tech Publ, pp. 471-476. doi:10.4028/www.scientific.net/MSF.347-349.471

Beck, H.P., Kaliba, C., 1991. High pressure investigations on $\mathrm{ZrO} 2$ doped with $\mathrm{Cr}$, Fe and $\mathrm{Nb}$. Mater. Res. Bull. 26, 145-152. 
Beck, H.P., Kaliba, C., 1990. On the solubility of $\mathrm{Fe}, \mathrm{Cr}$ and $\mathrm{Nb}$ in $\mathrm{ZrO} 2$ and its effect on thermal dilatation and polymorphic transition. Mater. Res. Bull. 25, 1161-1168.

Beckmann, R., Mella, R., Wenman, M.R., 2013. Mesh and timestep sensitivity of fracture from thermal strains using peridynamics implemented in Abaqus. Comput. Methods Appl. Mech. Eng. 263, 71-80. doi:10.1016/j.cma.2013.05.001

Bell, B.D.C., Murphy, S.T., Burr, P.A., Grimes, R.W., Wenman, M.R., 2015. Accommodation of tin in tetragonal ZrO2. J. Appl. Phys. 117, 84901. doi:10.1063/1.4909505

Berdin, C., Pascal, S., Tang, Y., 2015. Internal stresses at the crystalline scale in textured ZrO2 films before lateral cracking. J. Nucl. Mater. 460, 44-51. doi:10.1016/j.jnucmat.2015.01.056

Bossis, P., 2002. Study of the Mechanisms Controlling the Oxide Growth Under Irradiation: Characterization of Irradiated Zircaloy-4 and Zr-1Nb-O Oxide Scales, in: Zirconium in the Nuclear Industry: 13th ASTM STP 1423. Astm Intl, pp. 190-221.

Bossis, P., Lefebvre, F., Barbéris, P., Galerie, A., 2001. Corrosion of Zirconium Alloys: Link between the Metal/Oxide Interface Roughness, the Degradation of the Protective Oxide Layer and the Corrosion Kinetics. Mater. Sci. Forum 369-372, 255-262. doi:10.4028/www.scientific.net/MSF.369-372.255

Budiansky, B., 1983. Continuum theory of dilatant transformation toughening in ceramics. Int. J. Solids Struct. 19, 337-355.

Chan, Y.S.-K., Chan, S., Grimsditch, M., Li, Z., Nevitt, M. V, Robertson, W.M., Zouboulis, E.S., 1991. Temperature Dependence of the Elastic Moduli of Monoclinic Zirconia. J. Am. Ceram. Soc. 74, 1742-1744.

Chevalier, J., Gremillard, L., Virkar, A. V., Clarke, D.R., 2009. The Tetragonal-Monoclinic Transformation in Zirconia: Lessons Learned and Future Trends. J. Am. Ceram. Soc. 92, 19011920. doi:10.1111/j.1551-2916.2009.03278.x

Cox, B., 2005. Some thoughts on the mechanisms of in-reactor corrosion of zirconium alloys. J. Nucl. Mater. 336, 331-368. doi:10.1016/j.jnucmat.2004.09.029

Cox, B., Pemsler, J., 1968. Diffusion of oxygen in growing zirconia films. J. Nucl. Mater. 28, 73-78. doi:10.1016/0022-3115(68)90058-5

Deville, S., Guénin, G., Chevalier, J., 2004. Martensitic transformation in zirconia. Acta Mater. 52, 5709-5721. doi:10.1016/j.actamat.2004.08.036

Duwez, P., Brown, F.H., Odell, F., 1951. The Zirconia-Yttria System. J. Electrochem. Soc. 98, 356. doi:10.1149/1.2778219

Eichler, J., Eisele, U., Rödel, J., 2004. Mechanical Properties of Monoclinic Zirconia. J. Am. Ceram. Soc. 87, 1401-1403. doi:10.1111/j.1151-2916.2004.tb07748.x

Eichler, J., Rödel, J., Eisele, U., Hoffman, M., 2007. Effect of Grain Size on Mechanical Properties of Submicrometer 3Y-TZP: Fracture Strength and Hydrothermal Degradation. J. Am. Ceram. Soc. 90, 2830-2836. doi:10.1111/j.1551-2916.2007.01643.x

Eshelby, J., 1957. The determination of the elastic field of an ellipsoidal inclusion, and related problems. Proc. R. Soc. 241, 376-396.

Evans, A., Heuer, A., 1980. REVIEW-Transformation Toughening in Ceramics: Martensitic Transformations in Crack-Tip Stress Fields. J. Am. Ceram. Soc. 63, 241-248.

Fabris, S., Paxton, A.T., Finnis, M.W., 2002. A stabilization mechanism of zirconia based on oxygen vacancies only. Acta Mater. 50, 5171-5178.

Frankel, P., Wei, J., Francis, E., Forsey, A., Ni, N., Lozano-Perez, S., Ambard, A., Blat-Yrieix, M., Comstock, R.J., Hallstadius, L., Moat, R., Grosvenor, C.R.M., Lyon, S., Cottis, R.A., Preuss, M., 2013. The effect of Sn on corrosion mechanisms in advanced Zr-cladding for pressurised water reactors, in: Zirconium in the Nuclear Industry: 17th.

Fukuhara, M., Yamauchi, I., 1993. Temperature dependence of the elastic moduli, dilational and shear internal frictions and acoustic wave velocity for alumina, (Y)TZP and beta '-sialon ceramics. J. Mater. Sci. 28, 4681-4688. doi:10.1007/BF00414258 
Gaillard, Y., Jiménez-Piqué, E., Soldera, F., Mücklich, F., Anglada, M., 2008. Quantification of hydrothermal degradation in zirconia by nanoindentation. Acta Mater. 56, 4206-4216. doi:10.1016/j.actamat.2008.04.050

Garvie, R.C., 1978. Stabilization of the tetragonal structure in zirconia microcrystals. J. Phys. Chem. 82, 218-224. doi:10.1021/j100491a016

Garvie, R.C., Swain, M. V., 1985. Thermodynamics of the tetragonal to monoclinic phase transformation in constrained zirconia microcrystals - Part 1 In the absence of an applied stress field. J. Mater. Sci. 20, 1193-1200. doi:10.1007/BF01026313

Ghajari, M., lannucci, L., Curtis, P., 2014. A peridynamic material model for the analysis of dynamic crack propagation in orthotropic media. Comput. Methods Appl. Mech. Eng. 276, 431-452. doi:10.1016/j.cma.2014.04.002

Ghigna, P., Spinolo, G., Anselmi-Tamburini, U., Maglia, F., Dapiaggi, M., Spina, G., Cianchi, L., 1999. Fe-doped zirconium oxide produced by self-sustained high-temperature synthesis: Evidence for an Fe-Zr direct bond. J. Am. Chem. Soc. 301-307.

Guo, X., Schober, T., 2004. Water Incorporation in Tetragonal Zirconia. J. Am. Ceram. Soc. 48, 746748.

Heuer, A., Rühle, M., 1985. Overview no. 45: On the nucleation of the martensitic transformation in zirconia (ZrO2). Acta Metall. 33, 2101-2112.

Ho, C.-J., Tuan, W.-H., 2011. Phase stability and microstructure evolution of yttria-stabilized zirconia during firing in a reducing atmosphere. Ceram. Int. 37, 1401-1407. doi:10.1016/j.ceramint.2011.01.008

Hulme, H., Baxter, F., Babu, R.P., Denecke, M.A., Gass, M., Steuwer, A., Norén, K., Carlson, S., Preuss, M., 2015. An X-ray absorption near-edge structure (XANES) study of the Sn L3 edge in zirconium alloy oxide films formed during autoclave corrosion. Corros. Sci. 105, 202-208. doi:10.1016/j.corsci.2016.01.018

Jacquot, T., Guillén, R., François, M., Bourniquel, B., Senevat, J., 1996. Residual Stress of monoclinic zircon obtained by x-ray diffraction in ZY4 oxidized cladding tubes, in: Materials Science Forum. Trans Tech Publ, pp. 845-850.

Jiang, J.Z., Poulsen, F.W., Mørup, S., 1999. Structure and thermal stability of nanostructured irondoped zirconia prepared by high-energy ball milling. J. Mater. Res. 14, 1343-1352.

Kelly, P.M., Francis Rose, L.R., 2002. The martensitic transformation in ceramics - its role in transformation toughening. Prog. Mater. Sci. 47, 463-557. doi:10.1016/S0079-6425(00)00005-0

Keuper, M., Eder, K., Berthold, C., Nickel, K.G., 2013. Direct evidence for continuous linear kinetics in the low-temperature degradation of Y-TZP. Acta Biomater. 9, 4826-4835. doi:10.1016/j.actbio.2012.08.032

Kilic, B., Madenci, E., 2010a. Coupling of peridynamic theory and the finite element method. J. Mech. Mater. Struct. 5 .

Kilic, B., Madenci, E., 2010b. Peridynamic theory for thermomechanical analysis. IEEE Trans. Adv. Packag. 33, 97-105.

Kirchner, H.P., Gruver, R.M., 1981. Crack Branching in Transformation-Toughened Zirconia. J. Am. Ceram. Soc. 1979, 529-533.

Li, P., Chen, I., 1994. Effect of Dopants on Zirconia Stabilization-An X-ray Absorption Study: I, Trivalent Dopants. J. Am. Ceram. Soc. 77, 118-128.

Namavar, F., 2007. Thermal stability of nanostructurally stabilized zirconium oxide. Online.

Ni, N., Hudson, D., Wei, J., Wang, P., Lozano-Perez, S., Smith, G.D.W., Sykes, J.M., Yardley, S.S., Moore, K.L., Lyon, S., Cottis, R., Preuss, M., Grovenor, C.R.M., 2012. How the crystallography and nanoscale chemistry of the metal/oxide interface develops during the aqueous oxidation of zirconium cladding alloys. Acta Mater. 60, 7132-7149. doi:10.1016/j.actamat.2012.09.021

Ni, N., Lozano-Perez, S., Jenkins, M.L., English, C., Smith, G.D.W., Sykes, J.M., Grovenor, C.R.M., 2010. Porosity in oxides on zirconium fuel cladding alloys, and its importance in controlling 
oxidation rates. Scr. Mater. 62, 564-567. doi:10.1016/j.scriptamat.2009.12.043

Ni, N., Lozano-Perez, S., Sykes, J., Grovenor, C., 2011. Quantitative EELS analysis of zirconium alloy metal/oxide interfaces. Ultramicroscopy 111, 123-30. doi:10.1016/j.ultramic.2010.10.020

Ni, N., Lozano-Perez, S., Sykes, J.M., Smith, G.D.W., Grovenor, C.R.M., 2011. Focussed ion beam sectioning for the 3D characterisation of cracking in oxide scales formed on commercial ZIRLO ${ }^{\mathrm{TM}}$ alloys during corrosion in high temperature pressurised water. Corros. Sci. 53, 4073-4083. doi:10.1016/j.corsci.2011.08.013

Noguchi, K., Fujita, M., 1989. Tensile Strength of Yttria Stabilized Tetragonal Zirconia Polycrystals. J. Am. Ceram. Soc. 1305-1307.

Nono, M.C.A., 2005. Tetragonal-to-Monoclinic Transformation Influence on the Mechanical Properties of $\mathrm{CeO} 2-\mathrm{ZrO} 2$ Ceramics. Mater. Sci. Forum 498-499, 506-511.

Omar, A.H., Véronique, P., Eric, S., François, G., Jean, K., François, R., Michel, C., 2015. In situ high temperature oxidation analysis of Zircaloy-4 using acoustic emission coupled with thermogravimetry. J. Nucl. Mater. 461, 365-375. doi:10.1016/j.jnucmat.2015.03.014

Parry, V., Tran, M.T., Wouters, Y., 2013. Detection of breakaway oxidation with acoustic emission during zirconium oxide scale growth. Oxid. Met. 79, 279-288. doi:10.1007/s11085-012-9355-x

Petigny, N., 2000. In situ XRD analysis of the oxide layers formed by oxidation at $743 \mathrm{~K}$ on Zircaloy 4 and Zr-1NbO. J. Nucl. Mater. 280, 318-330. doi:10.1016/S0022-3115(00)00051-9

Platt, P., Allen, V., Fenwick, M., Gass, M., Preuss, M., 2015a. Observation of the effect of surface roughness on the oxidation of Zircaloy-4. Corros. Sci. 98, 1-5. doi:10.1016/j.corsci.2015.05.013

Platt, P., Frankel, P., Gass, M., Howells, R., Preuss, M., 2014. Finite element analysis of the tetragonal to monoclinic phase transformation during oxidation of zirconium alloys. J. Nucl. Mater. 454, 290-297. doi:10.1016/j.jnucmat.2014.08.020

Platt, P., Lunt, D., Polatidis, E., Wenman, M.R., Preuss, M., 2016. In-situ Digital Image Correlation for Fracture Analysis of Oxides Formed on Zirconium Alloys. Corros. Sci. 111, 344-351. doi:10.1016/j.corsci.2016.05.026

Platt, P., Polatidis, E., Frankel, P., Klaus, M., Gass, M., Howells, R., Preuss, M., 2015b. A study into stress relaxation in oxides formed on zirconium alloys. J. Nucl. Mater. 456, 415-425. doi:10.1016/j.jnucmat.2014.09.072

Platt, P., Wedge, S., Frankel, P., Gass, M., Howells, R., Preuss, M., 2015. A study into the impact of interface roughness development on mechanical degradation of oxides formed on zirconium alloys. J. Nucl. Mater. 459, 166-174. doi:10.1016/j.jnucmat.2015.01.028

Polatidis, E., Frankel, P., Wei, J., Klaus, M., Comstock, R.J., Ambard, A., Lyon, S., Cottis, R.A., Preuss, M., 2013. Residual stresses and tetragonal phase fraction characterisation of corrosion tested Zircaloy-4 using energy dispersive synchrotron X-ray diffraction. J. Nucl. Mater. 432, 102112. doi:10.1016/j.jnucmat.2012.07.025

Preuss, M., Frankel, P., Lozano-Perez, S., Hudson, D., Polatidis, E., Ni, N., Wei, J., English, C., Storer, S., Chong, K.B., Fitzpatrick, M., Wang, P., Smith, J., Grovenor, C., Smith, G., Sykes, J., Cottis, B., Lyon, S., Hallstadius, L., Comstock, R.J., Ambard, A., Blat-Yrieix, M., 2011. Studies Regarding Corrosion Mechanisms in Zirconium Alloys, in: Zirconium in the Nuclear Industry: 16th International Symposium ASTM STP 1529. pp. 649-681.

Qingping, S., Shouwen, Y., Kehchih, H., 1990. A micromechanics constitutive model for pure dilatant martensitic transformation of ZrO 2-containing ceramics. Acta Mech. Sin. 6, 141-150.

Scardi, P., Leoni, M., Loch, M., Barbezat, G., 2004. Elastic behaviour of thin stabilized-zirconia coatings. Mater. Sci. Forum 444, 77-82.

Shukla, S., Seal, S., 2005. Mechanisms of room temperature metastable tetragonal phase stabilisation in zirconia. Int. Mater. Rev. 50, 45-64. doi:10.1179/174328005X14267

Silling, S.A., 2000. Reformulation of elasticity theory for discontinuities and long-range forces. J. Mech. Phys. Solids 48, 175-209. doi:10.1016/S0022-5096(99)00029-0

Silling, S., Demmie, P., Warren, T., 2007. Peridynamic simulation of high-rate material failure, in: 
ASME Applied Mechanics and Materials Conference.

Stam, G., Giessen, E. Van der, Meijers, P., 1994. Effect of transformation-induced shear strains on crack growth in zirconia-containing ceramics. Int. J. Solids Struct. 31, 1923-1948.

Swan, H., Blackmur, M.S., Hyde, J.M., Laferrere, A., Ortner, S.R., Styman, P.D., Staines, C., Gass, M., Hulme, H., Cole-Baker, A., Frankel, P., 2016. The measurement of stress and phase fraction distributions in pre and post-transition Zircaloy oxides using nano-beam synchrotron X-ray diffraction. J. Nucl. Mater. 479, 559-575. doi:10.1016/j.jnucmat.2016.07.024

Teixeira, V., Andritschky, M., 1999. Analysis of residual stresses in thermal barrier coatings. J. Mater. Process. Technol. 93, 209-216.

Wang, X., Atkinson, a., 2011. Microstructure evolution in thin zirconia films: Experimental observation and modelling. Acta Mater. 59, 2514-2525. doi:10.1016/j.actamat.2010.12.056

Wei, J., Frankel, P., Polatidis, E., Blat, M., Ambard, A., Comstock, R.J., Hallstadius, L., Hudson, D., Smith, G.D.W., Grovenor, C.R.M., Klaus, M., Cottis, R.A., Lyon, S., Preuss, M., 2013. The effect of $\mathrm{Sn}$ on autoclave corrosion performance and corrosion mechanisms in $\mathrm{Zr}-\mathrm{Sn}-\mathrm{Nb}$ alloys. Acta Mater. 61, 4200-4214. doi:10.1016/j.actamat.2013.03.046

Wolten, G.M., 1963. Diffusionless Phase Transformations in Zirconia and Hafnia. J. Am. Ceram. Soc. 46, 418-422. doi:10.1111/j.1151-2916.1963.tb11768.x

Yilmazbayhan, A., Breval, E., Motta, A., Comstock, R., 2006. Transmission electron microscopy examination of oxide layers formed on Zr alloys. J. Nucl. Mater. 349, 265-281. doi:10.1016/j.jnucmat.2005.10.012

Yoo, H., 2001. A working hypothesis on oxidation kinetics of Zircaloy. J. Nucl. Mater. 299, 235-241. doi:10.1016/S0022-3115(01)00695-X

Zhang, H.X., Fruchart, D., Hill, E.K., Ortega, L., Li, Z.K., Zhang, J.J., Sun, J., Zhou, L., 2010. Crystal structure, corrosion kinetics of new zirconium alloys and residual stress analysis of oxide films. J. Nucl. Mater. 396, 65-70. doi:10.1016/j.jnucmat.2009.10.055

Zhou, M., 2003. A new look at the atomic level virial stress: on continuum-molecular system equivalence. Proc. R. Soc. A Math. Phys. Eng. Sci. 459, 2347-2392.

doi:10.1098/rspa.2003.1127 